\title{
Interaction Manifolds: Understanding Behaviour Around a Shareable Interface
}

\author{
Cecily Morrison \\ Cambridge University \\ William Gates Building \\ $15 \mathrm{JJ}$ Thomson Avenue \\ Cambridge CB3 OFD UK \\ (+44) 1223763783 \\ Cecily.Morrison@cl.cam.ac.uk
}

\begin{abstract}
This poster presents a suggestion for how ethnography of shareable interfaces might be used to inform subsequent design decisions by creating an analytical construct that we name the interaction manifold. We first describe and summarize results of our research to date in a medical intensive care unit. We then propose why and how an analytic construct might prove useful for design of shareable interfaces.
\end{abstract}

\section{Categories and Subject Descriptors \\ H.5.3 [Group and Organization Interfaces]}

\section{General Terms}

Performance, Design, Human Factors, Theory

\section{Keywords}

Shareable Interfaces, CSCW, Interaction Manifold

\section{INTRODUCTION}

The term, Sharable interfaces [1], has been proposed to describe a number of recent technology configurations that support collocated groups working with or around the same content but have little theoretical underpinning. One common example is interactive displays. The term also applies to medical environments where staff frequently gather around displays of patient medical records to discuss future treatment. In a recent study, we compared the non-verbal means with which the medical staff negotiate the interaction between themselves during the daily ward rounds while using a paperbased medical record and later a computer-based one. The result was a rich analysis of how the tenuous interaction between nurses and doctors, with a clearly hierarchical relationship, is accomplished in these two settings. Below we summarize the research and suggest that it can be generalized to support the design of sharable interfaces through articulating a concept we define and then refer to as the interaction manifold.

\section{BACKGROUND}

Medical situations necessitate a large number of staff coordinating their actions and communicating their findings.

(C) Cecily Morrison, 2007

Published by the British Computer Society Volume 2 Proceedings of the 21st BCS HCI Group Conference

HCI 2007, 3-7 September 2007, Lancaster University, UK Devina Ramduny-Ellis \& Dorothy Rachovides (Editors)
This is generally done with the help of the patient medical record. During the ward round, the medical record at the end of each bed, either in its paper form on the nurse's table or in its digital form displayed on a monitor, becomes the center piece of a complex interaction of ten or so staff of different ranks. The large number of people, and their different knowledge and rank require careful negotiation between the members to ensure that all useful information is revealed but the conversation is kept as short as possible. By negotiation we mean how a group mutually decides: (1) who can speak and (2) what the topic of conversation is [2]. Interaction negotiation is usually done nonverbally through what we refer to as physical interactions: group formation, upper-body orientation, gesture and object manipulation, and posture. Our analysis compares how physical interactions are used in negotiating who speaks and what is discussed during a ward round using the paper-based medical record and the computer-based one, highlighting the effect each type of record has on the communication.

\section{ANALYSIS}

The analysis of the group usage of the paper-based record showed how each of the physical interactions listed above played a role in determining who spoke and about what. We highlighted in particular, the ways the consultant (head doctor) directed the conversation and how the nurses contributed. Much of what we found fit into Kendon's framework describing group behaviour, the F-formation [3]. The computer-based record on the other hand, produced very different ways of communicating. The placement of the screen split the group formation into two, leaving only the aural channel connecting the members. This had the effect of requiring group members to use other means than physical interaction to negotiate the interaction: either interruption or through the technology (eg. leaving notes). There was a notable decrease in the amount of interaction between the nurses and the doctors. As different means of interacting are used in the computer-based record, Kendon's analysis does not seem to provide a sufficiently complete account for use as a basis for design decisions.

F-formation analysis assumes that the interaction content is expressed through social mechanisms expressed in the moment, verbally and bodily. In the computer-based scenario that we describe, device interaction becomes more prominent as an external motivating "force" that tends to modify the formation from outside this immediate social context. The interaction design of the computer-based system, together with the available structures for navigation of the online records, create trajectories of collaboration that are both visible and invisible. The available channels cross between the world of data relations "behind" the screen, and the configuration of 
actors who read and interact with the screen and each other. Our concern is to describe these more diverse structures in ways that take account of their inter-dependence rather than drawing misleading boundaries that might divide closely couple phenomena.

\section{FUTURE WORK}

That neither ethnography of the non-digital version of the shareable interface nor Kendon's analytic construct proved useful in understanding behaviour around the digital shareable interface, indicates the need for an alternative analytical construct to support the design of this shareable interface. The interaction manifold, as we would call it, would describe the tradeoffs of group negotiation abilities (ie. how different members of the group can enter the conversation and how the topic can be changed) depending on the number of displays, their size, their placement in place, the staticness of information on them, and the interaction possibilities. The analytical construct would provide designers a means to judge design decisions when creating a shareable interface, similar to Cognitive Dimensions [4] with notational design. I am currently working on this theoretical perspective.

Once the interaction manifold has been clearly developed, I plan to look at ways that motion captured data of movement during interaction might be used to support the analytical claims made. In order to demonstrate the power of the interaction manifold as an analytic construct for design, I will design a technology space, in which users can manipulate digital data projected on the wall through TUIs, while interacting with each other.

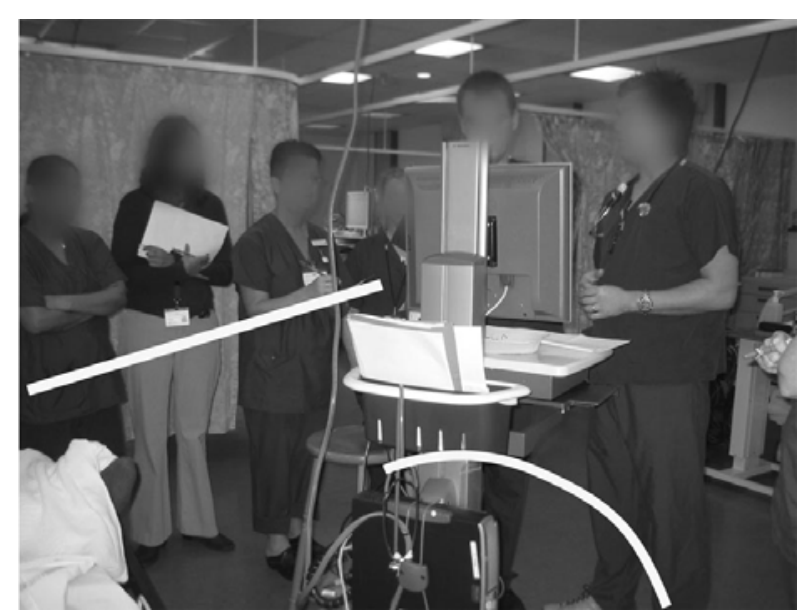

Figure 1. Group interaction around a computer-based medical record system

\section{ACKNOWLEDGMENTS}

We are grateful for the support of Papworth Critical Care Unit, Papworth Anaesthetic Research, and head consultant Alain Vuylsteke, who initiated this project. This research is sponsored by Boeing Corporation and IMDsoft, and is being conducted in collaboration with David Good and Alice McGowan (Social and Political Science) and Matthew Jones (Judge Business School).

\section{REFERENCES}

[1] Shareable Interface Workshop 2007 http://mcs.open.ac.uk/pm5923/si2007/

[2] Suchman, L. (1986): Plans and Situated Actions, Cambridge University Press, Cambridge, UK.

[3] Kendon, A. (1990): Conduction Interaction: Patterns of Behavior in focused encounters, Cambridge University Press, Cambridge, UK.

[4] Blackwell, A. F. Green, T.R.G (2003): “Notational Systems - the Cognitive Dimensions of Notations framework.” In J.M. Carroll (Ed.) HCI Models, Theories and Frameworks: Toward a multidisciplinary science. Morgan Kaufmann. 